\title{
Fiercely Real?: \\ Tyra Banks and the Making of New Media Celebrity
}

\author{
Corresponding author: Jessalynn Marie Keller \\ Department of Radio-Television-Film, University of Texas at Austin \\ 1 University Station A0800, Austin, Texas, USA 78712 \\ Phone: 512-471-4071 Fax: 512-471-4077
}

Author's contact information:

Department of Radio-Television-Film, University of Texas at Austin

1 University Station A0800, Austin, Texas, USA 78712

Phone: 512-461-2221

Email: Jessalynn.keller@gmail.com 


\begin{abstract}
:
This paper will examine former supermodel Tyra Banks as a contemporary "celebrity entrepreneur," focusing on Banks' recent shift from television persona to multimedia icon within a neoliberal popular culture. I argue that our contemporary new media environment, marked by convergent media texts, self branding, and interactivity provides an ideal space for Banks to produce and globally circulate her postfeminist star text. Through her websites, Facebook, and Twitter confessionals, Banks is able to successfully navigate the contradictory discourses that insist female celebrities be both "authentic" selves while maintaining a disciplined, hegemonic femininity that becomes legitimized and naturalized. I conclude that while Banks' mobilization of a hypervisibility and sense of individual agency generates an authenticity that may resonate with her fans, she remains contained by the neoliberal and postfeminist discourses that allow her to have such a prominent Internet presence. Consequently, this paper serves to raise unexplored questions about the relationship between celebrity culture, postfeminist and neoliberal subjectivities, and new media.
\end{abstract}

\title{
Keywords
}

postfeminism, neoliberalism, celebrity, new media, convergence culture

Having first gained popularity as a sultry supermodel in the mid-1990s, Tyra Banks became popular in part because of her positioning as a publicly visible raced $\underline{\text { and gendered body. She was the first African American cover model of Sports }}$ Illustrated Swimsuit Issue, $\underline{\mathrm{GQ}}$ and the Victoria's Secret catalogue, and is considered one of the first black models to find success within the predominantly white modeling world. Banks later proved to be a savvy businesswoman, branding herself through a host of media properties including the popular reality modeling show America's Next Top Model,(2003-present), her own talk show, The Tyra Show (2005-2010), and her extensive web presence, first at Tyra.com (2009-2011) and most recently at typeF.com (2011-present), as well as new endeavors, including a recent series of novels for teens. Banks, in this sense, is emblematic of what Kim Allen (2011) calls a "celebrity entrepreneur," who is able to invent herself through 
multiple media platforms and explain her success as indicative of ambition, talent, and hard work.

Recently, Banks has shifted her attention away from television, ending her Emmy-winning afternoon talk show and pursuing an extensive online presence on Tyra.com and typeF.com, a fashion and beauty website devoted to celebrating individual beauty and style. It is Banks' most recent shift to the online world that I will focus on here through a discursive and ideological textual analysis of her web presence, including Tyra.com, typeF.com, and supplementary presence on YouTube and Twitter. Banks' shift from supermodel to television personality to multimedia business tycoon may appear as proof of an increasingly progressive popular culture, where black women can attain longstanding celebrity status and the admiration of a mainstream white audience. In fact, Banks has utilized this rhetoric to position herself as a positive role model for girls, drawing on her own personal experiences as a sources of strength helping her to succeed in the cutthroat entertainment industry. It is this discourse I am interested in interrogating in this paper. How does Banks cultivate a subjectivity that celebrates authenticity based on individual choice and self-acceptance while maintaining a disciplined, yet naturalized hegemonic femininity acceptable to contemporary American ideals?

I maintain that the highly individualized nature of new media provides a particularly suitable platform for Banks to navigate the contradictory relationship between authenticity and a postfeminist, highly constructed, yet naturalized hegemonic hyper-femininity demanded of female celebrities. Through her use of various new media platforms, including her websites, Facebook, Twitter, and 
YouTube, Banks is seemingly able to speak directly to her fans through media platforms they frequent, promoting "fiercely real" bodies, a "uniquely you" sense of beauty, and "individual style" that hints at a celebration of non-normative bodies, a category in which she often includes herself. While having an online presence is now standard marketing practice for most celebrities, it is the way that Banks positions herself as an informed, authentic insider as she instructs her young female fans on how they can embrace their individual "type," that is pertinent to my discussion. I argue that Banks' personal claims to authenticity through social media allow her to naturalize and placate her brand's sustained promotion of highly disciplined female bodies that conform to normative notions of white femininity, while avoiding the critique levied at other female stars' for being "poor" role models for young girls. In this sense, Banks has been able to maintain a successful star text throughout her nearly two decades in the public spotlight, as evidenced not only by her recognized professional accomplishments and fan devotion, but also through her ability to reinvent herself across media platforms without alienating her teenage fans. I will argue that she is able to do this through her ongoing ability to appear progressive, while remaining neatly contained within larger normative constructions of feminine subjectivities rooted in postfeminist and neoliberal values made increasingly visible through their circulation online.

I will begin by outlining my theoretical framework, which draws on two recent subfields of media studies research, celebrity/star studies and new media studies. I connect these two subfields by demonstrating how postfeminist and neoliberal discourses inform both dominant discourses about female celebrities and 
new media practices. I theorize authenticity as being a central issue within this research and it is this idea that informs my analysis of Banks' online representations.

My discussion of Banks as a case study is based upon a close discursive and ideological textual analysis of Banks' websites, Twitter feed, and Facebook page over the period of several months in spring 2010 and spring 2011. My sample texts were purposefully chosen based upon their inclusion of themes and ideas that are privileged in postfeminist and neoliberal discourses, including authenticity/realness, empowerment, individuality, choice, and success. Thus, I specifically analyze texts that either used these exact words or draw on these ideas more generally in order to parse out how new media platforms provide a space for Banks to successfully navigate the contradictory relationship between an authentic self and an image that aligns with a marketable hegemonic femininity. I conclude this paper by contemplating questions of agency in relation to Banks' star text and online performances, and advocate for a better understanding of the relationship between celebrity culture, neoliberal and postfeminist discourses and new media.

\section{"Post-Identity" Politics and the Gendering of Fame in Contemporary Celebrity Culture}

Feminist media studies scholars have recently produced excellent work analyzing postfeminism as a sensibility shaping contemporary popular culture (Gill, 2007, McRobbie, 2009, Negra, 2009, Gill and Scharff, 2011). Postfeminism, according to this work, is understood as a cultural sensibility that promotes the 
"undoing" of feminism, through "disarticulation and displacement, accompanied by replacement and substitution" (McRobbie, 2009, 26, Gill, 2007). McRobbie argues that new forms of gender power in popular culture replace feminist politics, promoting a highly conservative mode of feminine 'empowerment', consumer citizenship, and sexual freedoms that are branded as progressive, yet continually celebrate hegemonic femininity as the ideal for women. Within this social and cultural context young women are positioned as flexible, individualized subjects "weighted towards capacity, success, attainment, enjoyment, entitlement, social mobility and participation," capable of unfettered success in the marketplace through hard work and dedication (McRobbie, 2009, 57).

The fashion and beauty industries are central to postfeminist femininity, and women are encouraged to "choose" to adhere to the norms dictated by them in order to mark oneself as an ambitious, empowered, and a desirable subject (McRobbie, 2009). According to McRobbie (2009) then, it is not male retribution but instead the fashion and beauty system, which becomes the new authoritative regime, encouraging women to undermine their supposed threat to men based on their new wage-earning power and visibility in the public sphere through an excessive, seemingly "ironic" display of normative feminine markers such as pencil skirts, stilettos, and corset tops. Femininity is consequently naturalized on the female body, which becomes the site of identity and "self" for women in these postfeminist discourses (Gill, 2007, Gill and Scharff, 2011, Tincknell, 2011).

Postfeminism exists in tandem with what scholars such as Ralina Joseph (2009) calls "post-race" logic, which posits that racism has been eradicated through 
the civil rights movement and consequently, race no longer matters as an identity category. Post-race, also referred to as "colorblind rhetoric," amongst other terms, has been thoroughly analyzed by critical race scholars, who argue that these discourses are problematic because they negate to recognize the very real history of racism which continues to affect people's lives, merely masking inequalities through denial of inequalities, rather than actively working to dismantle them (Crenshaw, 1997, Bonilla-Silva, 2003, Collins, 2005, Joseph, 2009).

Neoliberalism also structures the cultural context in which Banks develops her brand. Lisa Duggan (2003) argues that neoliberalism is not a "unitary system" but a "complex, contradictory cultural and political project created within specific institutions, with an agenda for reshaping the everyday life of contemporary global capitalism" (70). Neoliberalism is characterized by privatization, deregulation, a celebration of individualism, a rejection of the social welfare model of state governance, and it privileges choice, individual responsibility, freedom, selfimprovement, and personal empowerment. As scholars such as Rosalind Gill and Christina Scharff (2011) and McRobbie (2009) argue, neoliberalism is not gender neutral, but instead produces specific gendered subjectivities, often in accordance with postfeminist discourses, that confirm normative gender performances. It is this aspect of neoliberalism that I am particularly interested in exploring here in relation to Banks.

While I cannot provide a comprehensive analysis of postfeminism, post-race rhetoric, and neoliberalism here, they provide a significant cultural context for analyzing Banks as a celebrity figure. Indeed, in the introduction to In the Limelight 
and Under the Microscope Su Holmes and Diane Negra (2011) argue that the discursive circulation of women in the contemporary celebrity landscape warrants more attention from feminist scholars, particularly with regards to how discourses of postfeminism intersect with the subject of celebrity and the gendering of fame. Alice Marwick and danah boyd's (2011) understanding of celebrity is useful here. They theorize celebrity as an "organic and ever-changing performative practice rather than a set of intrinsic personal characteristics or external labels" and involving the "ongoing maintenance of a fan base, performed intimacy, authenticity and access, and construction of a consumable persona" (140). By employing the concept of celebrity in this way, we can ask how postfeminist discourses contribute to our understanding of female celebrities and the ways that female celebrities consciously perform and negotiate their star texts.

Scholars such as Joseph (2009) and Amy Adele Hasinoff (2008) have argued that Banks functions as both a postfeminist and post-race celebrity within a neoliberal culture, embodying and celebrating her positioning as a "post-identity everywoman" who is able to transcend the barriers of gender, race, and class through an empowered attitude and diligent work ethic. Joseph (2009) argues that Banks' positioning as "color-neutral" and empowered rather than feminist remains a structuring dimension of her celebrity. Despite one or two occasions where she has covertly challenged these post-discourses, Joseph (2009) maintains that Banks is ultimately contained by them. Likewise, Hasinoff (2008) argues that Banks' reality television program America's Next Top Model continually promotes a neoliberal racial visibility that "requires a profound blindness to current and historical racial 
injustices" (326). This research provides an important context for locating Banks as embodying both postfeminist and post-racial discourses and will serve as the foundation upon which my analysis is built.

While scholars such as Susan Bordo (1994) have demonstrated how women have always been associated with the body within the Western mind/body dualism, postfeminist discourses have further emphasized this connection, promoting the body as the primary site of femininity (Gill, 2007). As Kim Allen (2011) notes, this has been especially true within celebrity culture. She argues that the female celebrity body has increasingly become a site of "punitive surveillance," central to the construction of one's "authentic" selfhood (151). Allen (2011) maintains that this has created a double bind for female celebrities who are rewarded for "staying true to oneself," yet are also required to perform an accepted, hegemonic postfeminist femininity, consequently complicating the performance of an "authentic" celebrity selfhood.

In this sense, female celebrities that appear too contrived, artificial, or phony, especially if it manifests on their bodies through exaggerated plastic surgery for example, are often publicly ridiculed for trying too hard and "not being themselves." The negative press attention, including a People cover reading "Addicted to Plastic Surgery," published in early 2010 in reference to reality star Heidi Montag after it was reported she had 10 plastic surgery procedures in one day, is a recent example of this disciplining (Garcia, 2010). However, female celebrities are required to perform a postfeminist femininity characterized by hegemonic markers such as a tall, slim, hairless body, long (often blonde) hair, clear (usually white) skin, 
manicured nails, and are expected to be fashioned in expensive, trendy feminine clothes and accessories. While there is clearly labor involved in molding one's body to this standard, as well as a race and class component that positions wealthy whiteness as linked to this idealized femininity, Allen's (2011) argument implies that the labor must remain invisible or naturalized, making the performance of postfeminist femininity appear natural and authentic to certain individuals (Weber, 2009).

Two points are particularly relevant to my following discussion. Firstly, it is important to emphasize that for women and girls, authenticity is located in the body, reaffirming the body as central to female celebrity. This has certainly been the case with Banks, whose promotion of her body as brand has shaped her star text, even after retiring from modeling in 2005. Joseph (2009) argues, “Banks' body, and more specifically her breasts, remain starring characters in her many media appearances. Banks is rarely without a low-cut, décolletage-emphasizing outfit, as her breasts are indeed a major signifier of the Tyra brand" (240). Banks' "booty" has also become somewhat prominent in her brand identity since a 2007 episode where, after a tabloid magazine called her fat (endnote1), Banks retorted defiantly on her talk show, telling "all those who have something nasty to say to me or other women who are built like me: kiss my fat ass!" (Joseph, 2009). I will return later in my analysis to the way that Banks' promotion of her body, specifically her breasts, buttocks, and hair as signifiers of her authenticity as celebrity is performed and circulated. 
Second, Allen (2011) emphasizes that it is the self as individual who is celebrated within this discourse, aligning with a larger neoliberal project that privileges self-improvement as a means to "reveal" an inner, authentic self (Allen, 2011, Weber, 2009). As Brenda Weber (2009) argues in her book, Makeover TV: Selfhood, Citizenship, and Celebrity, the "after-body" in television makeover shows is always presented as one's true self, which has been (finally!) freed from one's past bad choices and poor bodily discipline. Despite viewers watching the contestant's transformation and the labor involved in this process, the authenticity of the "afterbody" is never questioned and is not understood as performed, but as "natural" (Weber, 2009). Thus, this tension that I have been discussing as indicative of a postfeminist culture, can also be seen as a result of a popular culture increasingly dominated by the neoliberal values of individualism, choice, and discipline.

\section{Celebrity, New Media, and Neoliberalism: Interrogating Intersections}

New media, including social networking sites such as Facebook, Twitter, YouTube, and easy-to-use blogging platforms, are indicative of what Henry Jenkins (2006) calls "participatory culture," a media culture characterized by "users" that engage in both consumptive and productive practices. These new opportunities for audience participation has fostered the personalization and individualization of media, where users can "custom order" their media based on their own needs and interests (Burgess and Green, 2009). Thus, new media has become a significant site for the production of individual identities, tastes, and display, and has led many scholars to understand new media as offering a democratic potential unlike 
previous mediums (Jenkins, 2006, boyd, 2008, Castells, 2009). For example, the Internet has been celebrated as relatively accessible and easy-to-use, for allowing users to become producers, and for its flexible architecture (Banet-Weiser, 2011). According to this perspective, new media fosters interactivity, participation, production, and creative identity-making that are central components of today's web. While challenges have been made to this perspective, such as work on surveillance by Marc Andrejevic (2007), the freedom and individual agency extended to web users remains a dominant theme in cultural studies scholarship on new media.

There has been little attention paid by new media scholars to the ways in which postfeminist and neoliberal values are manifest online. Existing work, however, draws some interesting connections between postfeminist, neoliberal values and new media. For example, Laurie Ouellette and Julie Wilson (2011) argue that rather than allowing for new identity subjectivities and pleasure for women, convergence culture often facilitates a form of neoliberal citizenship that merely repackages and promotes traditional gendered affective labor. Likewise, Sarah Banet-Weiser (2011) argues that new media platforms such as YouTube function as spaces where neoliberal brand culture, Web 2.0 interactivity, and post-feminism merge, creating a "contemporary interactive subject who realizes her individual empowerment through and within the flexible, open architecture of online spaces" (278). The similar logics and ideals of post-feminist and neoliberal subjects, including independence, capability, and empowerment, complement the neoliberal cultural space of the web, where individuals are awarded for innovative public 
performances through viral circulation, monetary compensation, and perhaps most importantly, celebrity.

The celebrity culture created around new media is significant, as both "average" citizens hoping to become celebrities and celebrities themselves utilize online spaces to make visible, promote, control, and rebrand their public image. Amy Shields Dobson (2008) notes that post-feminist "girl power" narratives rely on what Susan Hopkins (2002) calls "celebrity power" to create and update one's image as empowered and in control of one's self online. Dobson (2008) concludes that, "In commodified, 'celebrified' girl power culture, being a product in 'high circulation' is the ultimate achievement" (127). The self as a commodified product, then becomes indicative of a savvy business sense, a confidence in one's physical appearance and ultimately, a true, authentic self that is relatable to potential viewers and fans.

Scholars such as Anita Harris (2004), Dobson (2008), and Weber (2009) have all argued that contemporary media culture often relies on confessional narratives that serve to reveal a "true self" or an authentic identity, often the climax of a reality television show or a successful cam girl career. In demarcating a true self via confessional, these performances can be understood as creating individuals within a larger matrix of power (Foucault, 1978). Authenticity then, becomes intertwined with both star-making and individualization, as Weber (2009) argues in relation to makeover television shows. To Weber (2009), the reveal of an individual's authentic "inner celebrity" merely makes visible what's already there and challenges the commonly-held belief of celebrity as being fake, inauthentic, and unnatural. 
While authenticity has historically been a significant issue in attempting to understand stardom and celebrity in the film, music, and more recently television industries, scholars such as Su Holmes and Sean Redmond (2006), Alice Marwick and danah boyd (2011) and Elizabeth Ellcessor (2012) have recently argued that the concept has become even more important - and complex - in our new media environment. Ellcessor (2012) argues that, "Internet-based fame depends on the authenticity of a star's self-representation and on the notion of intimacy, experienced through the possibility of interaction rather than simple familiarity" (51). In this sense, authenticity becomes made evident through a new set of standards, which include illusions of "liveness," interactivity, a possible lack of media gatekeepers such as publicists, and spontaneity that supposedly allows celebrities to "disclose a 'real' version of themselves that reinforces their personas" (59).

Thus, by employing the concept of authenticity here and analyzing Banks' use of it, I am not suggesting that there is any kind of "real" Banks that we can actually know through her online media. Instead, I aim to better understand the way that Banks' performs the concept of authenticity in both a postfeminist cultural context that privileges authenticity as a necessary quality for female celebrities and a new media environment that offers distinctively new opportunities to perform it. This paper is then informed by a poststructuralist understanding of identity, which suggests that authenticity itself is not inherent and static, but is socially constructed, contextual, and performed (Marwick and boyd, 2011). 
The above discussion suggests that new media environments and formats require a new conceptualization of celebrity, where a desire for authenticity, constant access, and interactivity become bedrocks for the successful celebrity in contemporary popular culture. Alice Leppert and Julie Wilson's (2011) work on Lauren Conrad begins to map Conrad's star text within this cultural landscape, however their discussion of her in relation to her new media presence remains limited and focused on MTV's branding of Conrad online, rather than Conrad's own online initiatives. I aim to further interrogate this online space glossed over by Leppert and Wilson by focusing my analysis on Banks' online endeavors and examine Banks' own agency in producing and circulating her image via new media.

It is impossible to know whether or not it is the celebrity in question who is actively tweeting, posting, and commenting online. Ellcessor (2012) maintains, "New media forms, such as Twitter and other social media, encourage the notion they are immediate and authentic, but they are at base asynchronous, mediated forms of communication that can be easily falsified (66)." However, she reminds us that when the perceived traits of a celebrity are enacted in the "seemingly authentic and socially connected context of online social media, they cease to be perceived as performances (which may or may not be truthful) and become understood as evidence of backstage behaviour and a 'true' personality" (Ellcessor, 2012,60). Consequently, I am suggesting that because of the way that social media is commonly understood as inherently authentic within the public imagination, it may not matter if it is actually Banks behind the computer, as we are meant to read her online presence as authentic (Marwick and boyd, 2011). We can then look to Banks' 
presence on her website and social media platforms as evidence of her desired star text, which is the focus of my analysis.

\section{"The Real Me": Performing Authenticity on Tyra.com and YouTube}

Banks launched her online campaign, Beauty Inside Out (B.I.O.) in fall 2009, along with her rebranded website, Tyra.com. The first public initiative of the campaign was the "Fiercely Real" teen modeling competition, allowing "plus size" teenagers to compete on Banks' talk show in order to win the title of the "Fiercely Real" model winner, among other incentives. On her site Banks' writes, "the term 'Plus-sized' models sounds super old fashioned...so I'm changing the term 'Plussized and making it 'Fiercely Real'!' The pictures from the final shoot were posted on Banks' website and the first Fiercely Real winner, Sheridan Watson, a "17 yearold, size 14, fierce teen from New Jersey" was "crowned" in March 2010.

From the outset, Banks' B.I.O campaign appears to be a progressive, feminist approach to body image and media representation. After all, feminist research from the past thirty years has demonstrated the harmful effects of unrealistic media images on the confidence of girls and women (Bordo, 1993, Kilbourne, 1999). However, Banks' mission is clearly a commercial one. In her discussion of the 'Fiercely Real" competition she writes,

The average size of a woman in America is a size 14... It's my mission to expand the definition of beauty. To show unique, atypical, fiercely real, quirky, clumsy, five-headed girls through all of my many media projects and businesses. So watch out for what I have in store next! 
While Banks does invite girls to make a B.I.O. pledge on her website as to how they're going to rally against "unrealistic" media images, Banks' project appears to be more about her own celebrity persona and her "many media projects and businesses" than about feminist politics per se.

This becomes particularly evident in the language that she uses to discuss the campaign. There is a glaring absence of any reference to feminism or the long history of work by feminists to combat unrealistic images of women and girls in the media. There is also no mention of the many organizations throughout the United States and the world that are currently lobbying for more positive representations of women not just in terms of body size, but also in terms of race, ethnicity, sexuality, class, ability, and other identities. While it would make sense for Banks to use the connectivity that the web offers to link to other related feminist projects with the hopes of forming a broad coalition of media activists, she specifically chooses not to. Thus, Banks' project exists in isolation from feminist media activism and is instead represented as the brainchild of Banks as an individual mentor and businesswoman.

This individualized approach aligns with neoliberal and postfeminist values which celebrate the individual as the site where capacity, freedom, and change are enacted. According to McRobbie (2009), this sense of "female individualism" has replaced the collective strategies of feminism politics, and is easily accepted by mainstream society because it is non-threatening to a neoliberal economic and social system (16). Indeed, Banks' “female individualism" complements contemporary cultural norms through its disassociation from feminism and its 
embracing of empowerment, agency, choice, and entrepreneurial spirit disconnected from structural inequalities. By adopting this approach, Banks achieves a delicate balance, ensuring her brand is both non-controversial for a wide audience, yet seemingly modern, positive, and fun for her young fans.

Banks continually relies on the words "fierce" and "real" throughout her discussions of the B.I.O. campaign. The word "fierce" is an interesting choice for several reasons. While Banks has recently appropriated the term, the word has a longer history within queer communities to describe "anything exceptional" (Queers United Blog, 2009). Gay men of color, such as America's Next Top Model judge and runway coach Miss J Alexander, were primarily responsible for integrating it into the fashion industry, where it shifted to become a more mainstream word. Considering its history as a word from the margins, Banks' reliance on "fierce" raises several interesting implications. First, it potentially alludes to her own marginalized position as a black woman in a media industry dominated by white men, as well as the marginalized position of her "fiercely real" sized teen models in an industry dominated by thin, white women. Second, it potentially allies her with the queer community, where she has been recognized with the 2009 Excellence in Media Award from the Gay \& Lesbian Alliance Against Defamation (GLADD). She also employs several openly gay men on her Top Model team, and has featured several lesbian and one transgendered contestant (endnote 2).

But despite the potential challenge to dominant white heterosexual norms carried by the term, Banks does not use 'fierce' in oppositional, resistant, or political ways, adopting the word as a way to demonstrate her own individual authenticity 
rather than call attention to structural inequalities faced by African Americans and queer people. This is evident not only through her lack of acknowledgment of power relations that privilege certain bodies, but also through the way she employs the word to merely promote a normative white, feminine gender performance celebrated in the Beauty Inside Out campaign. For example, in March 2010 Banks writes on Tyra.com that, "This week is all about being natural. Real. The real you." She continues to instruct her visitors,

You see the pictures on the cover this week? I'm $\underline{\text { barely }}$ wearing any make-up and I got the real hair goin' on (with a relaxer of course)... So stop trying to please everyone else by being a slave to lots of make-up this week. Walk around with your head held high and show off that fabulous skin. Of course I don't expect you to go to school or work with no make-up, but maybe on a Saturday out to the grocery store you could keep your fresh face and just add some clear lip-gloss! Think of it as a way to the inner you. Tell me how YOU get unmasked! Fierce \& Love, Tyra (bold emphasis in original text)

Banks' contradictory prescriptions for beauty here must be analyzed in relation to her audience. By suggesting to her teenage girl fans that "being a slave to lots of make-up" is not the only option for girls, Banks is presenting an idea that contradicts many of the media messages that girls receive about normative feminine beauty practices. I am suggesting that while this action can be read as both resistant and progressive, Banks' agency is limited by her need to continually appeal to a broad audience of girls that may not be receptive to a complete rejection of beauty norms. Thus, the potentially resistant message of rejecting makeup is recuperated through her suggestions to go make-up free on Saturdays or to just wear clear lip gloss. 
While Banks' suggestion to "add some clear lip-gloss" may send the signal to be more natural, it also implies the importance of still being adequately feminine and assumes that one has clear lip-gloss, that it is part of every girl's make-up essentials. Furthermore, her disclaimer that of course she doesn't "expect you to go to school or work with no make-up" maintains traditional ideas about feminine beauty - that in the formal public sphere, women must still be clearly feminine. In other words, despite coming close to offering a resistant stance against dominant beauty norms, Banks ultimately ends up enforcing normative femininity as a must for those women and girls wanting to be successful in the marketplace, and Banks continually presents this performance of femininity as a natural and innate quality of being female.

The accompanying pictures of Banks and her "Fiercely Real" model winner that flash continuously on her website also reflect traditional notions of feminine beauty: their eyes and lips are made up, their hair is sleekly styled, their skin airbrushed to flawless perfection. While Watson's body is indeed larger than Banks', her proportions mirror a perfect hourglass figure and it appears as though she doesn't have any excess body fat. But perhaps most striking is the bright lighting shining down on the two women. Although both Banks and Watson are black, their skin appears to be almost white and their features conform to white standards of feminine beauty, most notably, sleek, straight hair.

Despite Banks' rhetoric about loving and embracing your "real" body, Banks is known for always wearing a hair weave and having her hair relaxed. Her comment above, that she's "got the real hair goin' on (with a relaxer of course)" 
indicates that her hair relaxer is non-negotiable, an assumed part of her "real" beauty. Banks further emphasizes this contradictory logic on the premiere of the fifth season of The Tyra Show, where she garnered widespread media attention for revealing her "real" hair on-air, telling her fans, "I wanted to show the real me, I wanted to show the raw me. And I just got out of the shower - beat the face first of course, y'all - and came out here on this stage, and this is me, y'all!' The next day, Banks made headlines with her revelation, with celebrity glossies covering the "story." The video of Banks' reveal, marketed by the CW as one of the "Top 10 Tyra Show" moments, continues to circulate on YouTube as a much commented on clip.

While Banks' discourse positions her body as "real" and "natural" within both of the above examples, a closer examination of Banks' mediated image reveals her simultaneous promotion of a very specific, traditionally feminine beauty that must be actively constructed and maintained through beauty products and maintenance routines. For example, when revealing her "real" hair Banks notes that despite just getting out of the shower, she "beat the face first of course, y'all." In other words, a full face of makeup was an unquestioned necessity for stepping onto the stage, despite the theme of the episode being all about naturalness.

Furthermore, while Banks may be weave-free, her hair is still chemically relaxed, conforming to the longstanding tradition of African American hair straightening and signifying that Banks' hair discourse is clearly about issues of racialized beauty (Walker, 2007). But Banks refuses to frame it as such, instead positioning her hair relaxing as a personal choice, equivalent to putting on lipgloss and affirming a neoliberal post-race project, where black women are 
entitled to choose whether to relax their hair, divorced from the broader political and social implications that this decision may imply. Thus, Banks' "real" self is still a carefully constructed performance of an "appropriate", contained, non-threatening black femininity (Banet-Weiser, 1999).

While this non-threatening black femininity is comfortably apolitical in it's conforming to white beauty standards, Banks' performance continually reaffirms her authentic blackness, which is necessary for her commercial appeal. For example, Banks will often interject what Susan Douglas (2010) calls "Black Speak" into her performances, such as when she tells the audience at her real hair episode that she, "beat the face, of course, y'all" (148). While Banks does not often make explicit reference to herself as a black woman in terms of a social position within hegemonic power relations, these moments assure Banks' viewers that she is, indeed, authentically black. This "aura" of authentic blackness is central to Banks' presentation of her "real self", which ultimately maintains her high market value (Benjamin, 1984, Allen, 2011).

In her discussion of Oprah, Douglas (2010) argues that code-switching between "standard white English" and "Black Speak," "not only marks herself as cool and authentic but also includes the white audience in her hip community" (148). This is also true of Banks, whose mainstream appeal includes a diverse audience of primarily teenage girls and young women. According to Helene A. Shugart (2007), this confirmation of authenticity often becomes important for celebrities of color in order to maintain a crossover appeal to a mainstream - read, white - audience. "Authentic blackness" becomes indicative of a "white fascination" with and desire 
for black expression which Watts and Orb (2002) argue, serves to ensure its availability for containment, commodification and consumption.

In other words, white girls - a key target demographic for advertisers - can comfortably enjoy Banks' Black Speak as something cool and edgy, while their own white privilege goes unchallenged and white hegemonic femininity is secured as the desired norm. Thus, a performance of authentic blackness, or authentic otherness, is not a liability, but often a necessity for non-White celebrities that aim to gain a large, mainstream following of fans, as we've witnessed in the case of Oprah and Jennifer Lopez (Douglas, 2010, Beltran, 2007, Shugart, 2007). Conveniently, this performance also works within the logic of post-racial discourse, framing racial markers as edgy, ethnic, marketable accessories to a mainstream audience craving something a little different, while positioning Banks herself as a "successful Everywoman", albeit one who just happens to be black (Douglas, 2010).

By conducting her B.I.O. Campaign online, Banks draws on the participatory capacity of social network platforms to reach out to her girl fans, encouraging them to join her in her campaign. Indeed, the participation of her fans is necessary for many of her projects, such as the "Fiercely Real" modeling competition, which relies on girls' photo submissions and active participation in the contest by posting advertisements for it on their social networking profiles and logging onto Banks' site to comment on the winner. Based upon this participatory element, I am suggesting that a seemingly more personal and intimate relationship is built between Banks and her fans, one that positions Banks as an accessible online friend, reaffirming her image as someone who is real, authentic, and genuine, rather than a 
superficial persona on a TV screen or magazine page. It is this ability of Banks to be seen as "real" by posting personalized messages, constantly circulating new content, and even responding to fan's requests on her message board, that serves to maintain her current fan base and relevance in popular culture.

\section{“Welcome to a Revolution": Celebrating Individuality on typeF.com and Twitter}

In April 2011 Banks launched her newest online endeavor, typeF.com, a comprehensive website devoted to fashion and beauty. Visitors to the site are greeted with a pop-up message from Banks warning you to "get ready to join in revolutionizing the world of fashion and beauty" with Banks promising, "typeF.com continues my goal of expanding the definition of beauty." The site is similar to most other beauty and fashion websites, offering blog-style posts on the latest fashion trends, newest make-up and hair tricks, celebrity style, and beauty products. Banks attempts to differentiate herself from this oversaturated market by appealing to the logic of individual beauty. According to this perspective promoted by Banks, every woman is unique and should not have to conform to one narrow standard of physical beauty, but instead embrace one's own beauty through unique practices and products catered to each individual. As Banks says in her introductory blog post,

Like many pioneering women before me, including Arianna Huffington, I believe I have both a responsibility and the opportunity to give women a new view of themselves. For a long time, the fashion world defined my "type." I want to define what type of woman I am. I don't want a few editors to dictate my style; I want it to be more personal. Making things more personal always 
makes them more powerful.

Thus, visitors are encouraged to create their own personalized profile where they will be given tips tailored to their own beauty and fashion needs, tips based on their perceived "type" which will supposedly help them better navigate the complex rituals of the world of beauty and fashion demanded by postfeminism.

Banks' rationalization of the site's mission shifts her own position from a television expert, who dispenses advice with little interaction with her subject, to an online trailblazing guide, someone who is a real friend, a trusted confidante looking out for her fan's best interests, and harnessing the best use of technology to do so. Thus, Banks claims to mobilize her own body and experiences in the service of helping her fans deal with their own body insecurities. She blogs,

In the modeling business, I definitely was a type. That's how the business works (I am happy that my type just happened to be one with curves where most had none!). But now, I strive to break my stereotype, everyday. I hope I can empower women to break theirs. When anyone tells you what "type" of person they think you are, it is personal. Let's decide our own type no matter how fierce, fabulous, fun or feisty it may be.

Similar to Banks' framing of her B.I.O. campaign, Banks' rhetoric of the individual on typeF.com operates through the delicate contradiction I elaborated on previously: the celebration of a real, authentic individual beauty while also promoting traditional standards of femininity and bodily maintenance. For example, a February 27, 2011 blog post titled "How to Cover a Raised Scar on the Face" by Glenda Taylor states,

Real beauty comes in all shapes and sizes, and yes, even in facial scars. While you can minimize the appearance of a raised scar with makeup, don't let the 
Ms. Perfect inside you tell you that you're anything less than fabulous if you don't. Hide the scar only if it boosts your self-confidence, then tell that shallow twit to take a hike. Baby, you're the bomb!

The post then proceeds to provide step-by-step makeup advice for how to cover a facial scar, with sidebar advertisement for makeup brands like L'Oreal. But while there are even contradictory logics at work within this single posting (a celebration of not needing to cover up a facial scar, followed by advice on how to cover it, all sandwiched beside advertising for L'Oreal's new foundation) the opening tone is celebratory, positive, and perhaps for some, empowering. It presents the body as something to embrace and feel comfortable in.

However, this feel-good logic is challenged in a blog post dated April 26, 2011 by Antonia Blyth titled “It's Genetic: Skin Care Tailored to You: Inherit Your Mother's Wisdom - Not Her Wrinkles", which instructs readers that "dreaded sagging and thin skin" can be avoided through "preventative care and the right products." The blog post goes on to detail seven steps to "keeping you young looking" as well as a sidebar warning readers of "Signs of Aging in Your 20s and 30s." Blog posts such as this one serve as somewhat of a disciplinary rod should readers get too comfortable in accepting their real bodies: gone is the celebratory tone about the body, replaced instead with a warning about the necessity of feminine bodily maintenance and underscoring the natural aging process as something that should be actively resisted through the purchase of products and the labor of beauty. 
If Banks is reliant on promoting consumptive fashion and beauty practices, why does she continue to utilize a discourse of authenticity and a celebration of natural beauty as key to her star text? Banks' emphasis on the importance of "real" beauty - an "authentic beauty" - is necessary in order to deflect attention away from her carefully constructed performances of feminine beauty. As a former supermodel and the host and creator of a modeling show, Banks must be cautious to avoid promoting dangerous and unrealistic standards of beauty to her young fans, which would no doubt tarnish her image as role model and knowledgeable big sister, images that Banks actively cultivates on both Tyra.com and TypeF.com. The message of authentic beauty is unproblematic to a variety of audiences - her girl fans, their mothers, and even feminist critics - because it seemingly promotes loving oneself as one already is.

It is important to recognize that Banks' authentic beauty aligns with the corporate branding of Cover Girl Cosmetics, for whom Banks is a former spokesperson. Cover Girl is a major sponsor for Top Model, and the cosmetics manufacturer also uses words like "natural" and "fresh" to sell its products. Perhaps in order to preserve this relationship, Banks' celebration of unique, authentic beauty remains purposefully vague, and certainly does not dismiss feminine beauty practices. Instead, Banks encourages readers to tweak these practices to better suit their own needs and, like the makeover shows described by Weber (2009), to merely reveal their natural beauty. 
Banks' typeF.com provides a particularly rich example of the unique way that online space allows for the circulation of neoliberal celebrations of the individual. Banks acknowledges this in her first blog post, writing,

Listening to and studying consumers has given me a great appreciation for what problems women are looking to solve. The online fashion and beauty space is fragmented, mostly because there are so many types of women. We at typeF.com will be able to give them tailored answers by using Facebook as the personalization platform. My intention is to create a site, and a movement, for and based on all types of women.

In this sense typeF.com is more than a solitary website, but a hub for a larger network of the Banks celebrity brand, which is extended through Tyra.com (now only accessible through the typeF.com website), Facebook, Twitter, and YouTube and is indicative of the hypervisibility that scholars such as Banet-Weiser (2011) argue is symptomatic of a postfeminist and neoliberal new media culture.

For example, visitors to typeF.com can connect their Facebook accounts to the site, allowing for easy circulation of typeF.com postings, or choose to follow typeF.com or Banks herself on Twitter. Banks' personal Twitter feed is indicative of a popular trend amongst celebrities to boost their image and increase publicity through constant tweets, such as in the case of Charlie Sheen, who recently garnered over a million followers within twenty-four hours of opening a Twitter account.

Banks often uses her Twitter feed (connected to both typeF.com and Banks' Facebook page) to make mundane comments about her day, to connect with her fans, or to further promote her B.I.O. agenda. For example, an April 24, 2011 tweet reads: “Page 35 NY Post 2day. Actress Ana De La Reguera w/real 1950’s type curves. Gorgeous! Check it out!" While an April 30, 2011 retweet from Banks confirms that 
she does follow her fans on Twitter: “RT @britdomingue: @tyrabanks is pretty awesome \#justsayin Do you follow fans? - YES! CONSIDER YOURSELF JUST

FOLLOWED!” These types of online interactions help to further develop Banks as an authentic celebrity in touch with her fans, who can learn what movie Banks watched last weekend or what she's eating for breakfast by following her on Twitter. Thus, these online platforms are particularly useful for Banks who has new avenues to develop authenticity through instantly circulating messages twenty-four hours a day, seven days a week.

\section{Conclusions and Implications: From 'Fierce' to Farce?}

Throughout this discussion I have shown how Banks has used online space to negotiate the central contradiction of her star text: her strategy to be seen as a real, natural, authentic, and accessible friend to her fans and her sustained adherence to hegemonic feminine beauty norms requiring ongoing bodily discipline and labor. This dilemma is not unique to Banks, but is a common tension for today's female celebrities that Banks has successfully held in check, in part, via her use of new media platforms (Allen, 2011, Weber, 2009). I am suggesting then, that my discussion points to the need for a new conceptualization of female celebrity, one that takes into account how a new media cultural context supported by postfeminist notions of empowerment and the individualist values of neoliberalism privileges female celebrity subjectivities that can be read as real and authentic, yet unable to disrupt the dominance of hegemonic, white femininity. 
As I demonstrate in this paper, Banks maintains her authenticity by mobilizing a feminine, confessional-like rhetoric that is made hypervisible through a constant circulation of tweets, blog postings, and images. Banks' constant revealing, whether blogging about coming to terms with her own "curvy" body or posting photos of herself sans makeup, successfully utilizes the "flexible, open architecture of online spaces" as a strategy to maintain a realness and closeness with her girl fans on platforms that they frequent in their everyday lives (Banet-Weiser, 2011, 278, Ellcessor, 2012). The confessional has become a popular online practice over the past decade, as can be seen in the popularity of cam-girl culture, online diaries and journals like LiveJournal, and even Facebook status updates. And while the confessional has also been a central component of reality television shows, it is the lack of intermediary such as an editor or a structural factor such as a time limit that differentiates the online confessional from its television counterpart. Individuals are, at least seemingly, in control of their own online image and can be celebrated as such. In this sense, Banks' use of what I'm calling the "virtual confessional," that relies on hypervisibility and a sense of individual agency generates an authenticity that other female celebrities, such as Kim Kardashian, have failed at maintaining (endnote 3).

While the participatory and seemingly democratic functions of the Internet may appear to offer female celebrities like Banks increased agency and perhaps even the ability to challenge gender and race barriers to the entertainment industry, I question this assumption based on my analysis of Banks. While claiming to offer her fans insight into the real her, Banks is able to naturalize and placate her brand's 
sustained promotion of highly disciplined female bodies that conform to normative notions of white femininity. Banks' confessional then serves in much the same way as Michel Foucault (1978) conceptualizes it. Her virtual confessional functions as a disciplining structure that legitimizes her as an individual, yet keeps her safely contained within the dominant power structures of patriarchy, racism, and classism. Thus, the sense of individual agency that generates Banks' claim to authenticity is seemingly limited by the discursive positions offered to her within our postfeminist and neoliberal culture. Perhaps ironically, it is this rhetoric of individualism, empowerment, visibility, and authenticity that has allowed her to seamlessly translate her celebrity online and navigate the web so successfully.

There is little scholarly work that examines the intersection of celebrity and critical Internet studies, and it is my intention to begin to map some of the relevant issues here. Using Banks as a case study it is possible to see the ways in which the dominant discourses of both neoliberalism and postfeminism shape and construct the discursive positioning of female celebrities, even in an era seemingly marked by the freedom of new media platforms. While the Internet may indeed more easily allow for celebrities like Banks to negotiate the demands placed on them, such as the need to be authentic yet conform to disciplined femininity, it is essential to be critical of the intersection of new media and the production of neoliberal and postfeminist subjectivities. Thus, I am suggesting that more research be done examining how these discourses support our understanding of new media as offering individual choice, agency, empowerment, and authenticity. 


\section{Acknowledgments}

I'd like to thank Dr. Nhi Lieu, Dr. Janet Davis and Dr. Mary Celeste Kearney at the University of Texas at Austin for their useful comments on earlier drafts of this paper. Also special thanks to Morgan Blue for her keen editing eye and insightful suggestions to improve this paper. Finally, I'd like to thank the reviewers for their useful comments and constructive feedback throughout the editing process.

\section{Endnotes}

(1) This "scandal" erupted after photos of Banks wearing an ill-fitting swimsuit on a beach were leaked in the press. Several celebrity glossies and tabloid magazines picked up the story, chastising Banks for gaining weight and calling her "fat." Interestingly, this is one of the few times Banks has been covered in these types of publications.

(2) The progressive possibilities of gay representation on Top Model arguably remain limited, as gay men are already assumed to be interested in fashion and style. Thus, Banks is not necessarily challenging stereotypes with queer representation on her show.

(3) After she announced her divorce after only 72 days of marriage and an estimated ten million dollar wedding that was showcased on E!, reality star Kim Kardashian was harshly criticized in the press for her "sham marriage" that further cemented her public reputation as being inauthentic, and fame-hungry (Peyser, 2011).

\section{Works Cited}

Aalten, Anna. (1997) "Performing the Body, Creating Culture" in Embodied Practices: Feminist Perspectives on the Body, ed. K. Davis, Sage, Thousand Oaks, 41-58.

Allen, Kim. (2011) "Girls Imagining Careers in the Limelight: Social Class, Gender, and Fantasies of 'Success'” in $\underline{\text { In the Limelight and Under the Microscope: }}$ Forms and Functions of Female Celebrity, ed. S.Holmes and D. Negra, Continuum, London, 149-173.

Andrejevic, Mark. (2007) iSpy: Surveillance and Power in the Interactive Era, University of Kansas Press, Lawrence. 
Banet-Weiser, Sarah. (1999) The Most Beautiful Girl in the World: Beauty Pageants and National Identity University of California Press, Los Angeles.

(2011) “Branding the Post-Feminist Self: Girls' Video Production and YouTube" in Mediated Girlhoods: New Explorations of Girls Media Culture, ed. M.C. Kearney, Peter Lang, New York, 277-294.

Beltran, Mary. (2007) "The Hollywood Latina Body as Site of Social Struggle: Media Constructions of Stardom and Jennifer Lopez's 'Cross-over Butt' " in Stardom and Celebrity: A Reader, eds. S. Redmond and S. Holmes, Sage, Thousand Oaks, 275-286.

Benjamin, Walter. (1984) "The author as producer" in Art After Modernism, ed. B.Wallis, The Contemporary Art Museum, New York, 297-310.

Blyth, Antonia. (2011) "It's Genetic: Skin Care Tailored to You" typeF.com, [Online] Available at: http://www.typef.com/article/s-genetic-skin-care-tailored/

Bonilla-Silva, Eduardo. (2003) Racism Without Racists: Color-blind Racism and the Persistence of Racial Inequality in the United States, Rowman \& Littlefield, Lanham, MD.

Bordo, Susan. (1993) Unbearable Weight: Feminism, Western Culture, and the Body, University of California Press, Los Angeles.

boyd, danah. (2008) "Why Youth (Heart) Social Network Sites: The Role of Networked Publics in Teenage Social Life" in Youth, Identity, and Digital Media, ed. D. Buckingham, MIT Press, Boston, 119-42.

Castells, Manuel. (2009) Communication Power, Oxford University Press, New York.

Collins, Patricia. (2005) Black Sexual Politics: African Americans, Gender, and the New Racism, Routledge, New York.

Crenshaw, Kimberle. (1997) 'Color-blind Dreams and Racial Nightmares: Reconfiguring Racism in the Post-Civil Rights Era' in Birth of a Nation 'hood: Gaze, Script, and Spectacle in the 0.J. Simpson Case, ed. T. Morrison, Pantheon, New York, 97-168.

Dobson, Amy. (2008) "Femininities as Commodities: Cam Girl Culture" in Next Wave Cultures: Feminism, Subcultures, Activism, ed. A. Harris, Routledge, New York, 123-148.

Douglas, Susan. (2010) Enlightened Sexism: The Seductive Message that Feminism's Work is Done, Times Books, Henry Holt and Company, New York. 
Duggan, Lisa. (2003) The Twilight of Equality: Neoliberalism, Cultural Politics and the Attack on Democracy, Beacon Press, Boston.

Dye, Lauren. (2009) 'Consuming Constructions: A Critique of Dove's Campaign for Real Beauty' Canadian Journal of Media Studies, vol. 5, no. 1, Available at: http://cjms.fims.uwo.ca/issues/05-01/index.html.

Dyer, Richard. (1986) Heavenly Bodies: Film Stars and Society, MacMillan, Hampshire, England.

Ellcessor, Elizabeth. (2012) 'Tweeting @feliciaday: Online Social Media, Convergence, and Subcultural Stardom' Cinema Journal, vol. 51, no. 2, pp. 4666.

Foucault, Michel. (1978) The History of Sexuality, Volume 1, Random House, New York.

Garcia, Jennifer. (2010) 'Heidi Montag: Addicted to Plastic Surgery' People.com, Available at: http://www.people.com/people/article/0,,20336472,00.html.

Gill, Rosalind. (2007) Gender and the Media, Polity, Malden, MA.

Gill, Rosalind and Schraff, Christina. (2011) New Femininities: Postfeminism, Neoliberalism and Subjectivity, Palgrave Macmillan, New York.

Harris, Anita. (2004) Future Girl: Young Women in the Twenty-first Century, Routledge, New York.

Hasinoff, Amy Adele. (2008) 'Fashioning Race for the Free Market on America's Next Top Model', Critical Studies in Media Communication, vol. 25, no. 3, pp. 324343.

Holmes, Su and Redmond, Sean. (2006). Framing Celebrity: New Directions in Celebrity Culture, Routledge, New York.

hooks, bell. (1992) Black Looks: Race and Representation, South End Press, Boston.

Hopkins, Susan. (2002) Girl Heroes: The New Force in Popular Culture. Pluto Press Australia, Annandale, NSW.

Jenkins, Henry. (2006) Convergence Culture: Where Old and New Media Collide, New York University Press, New York.

Joseph, Ralina. (2009) “Tyra Banks Is Fat': Reading (Post-)Racism and (Post)Feminism in the New Millennium', Critical Studies in Media Communication, vol. 26, no. 3, pp. 237-254. 
Kilbourne, Jean. (1999) Deadly Persuasion: Why Women and Girls Must Fight the Addictive Power of Advertising, Simon and Schuster, New York.

Leppert, Alice. and Wilson, Julie. (2011) 'Living The Hills Life: Lauren Conrad as Reality Star, Soap Opera Heroine, and Brand' in In the Limelight and Under the Microscope: Forms and Functions of Female Celebrity, ed. S.Holmes and D. Negra, Continuum, London, 261-279.

Marwick, Alice. and boyd, danah. (2011) 'To See and Be Seen: Celebrity Practice on Twitter' Convergence: The International Journal of Research into New Media Technologies, vol. 17, no. 2, pp.139-158.

McRobbie, Angela. (2009) The Aftermath of Feminism: Gender, Culture, and Social Change, Sage, Los Angeles.

Negra, Diane. (2009) What a Girl Wants? Fantasizing the Reclamation of Self in Postfeminism, Routledge, New York.

Ouellette, Laurie. and Wilson, Julie. (2011) ‘Women's Work: Affective Labor and Convergence Culture' Cultural Studies, vol. 25, no. 4-5, pp. 548-565.

Peyser, Andrea. (2011) 'For Richer, or Richer: Inevitable Collapse of a Sham Marriage" in New York Post, Available at http://www.nypost.com/p/news/national/for_richer_or_richer_inevitable_E dQ1pwqg1BR7ZoXjp3dJWL.

Queers United Blog. (2009) 'Word of the Gay: Fierce', Available at: http://queersunited.blogspot.com/2009/02/word-of-gay-fierce.html.

Shugart, Helene. (2007) 'Crossing Over: Hybridity and Hegemony in the Popular Media' Communication and Critical/Cultural Studies, vol. 4, no. 2, pp. 115141.

Taylor, Glenda. (2011) 'How to Cover a Raised Scar on the Face', typeF.com, Available at: http://www.typef.com/article/cover-raised-scar-face/.

Tincknell, Estella. (2011) 'Scourging the Abject Body Ten Years Younger and Fragmented Femininity under Neoliberalism' in New Femininities: Postfeminism, Neoliberalism and Subjectivity, ed. R. Gill and C. Schraff, Palgrave Macmillan, New York, 83-95.

TypeF.com (2011-). http://www.typeF.com.

Tyra.com (2009-2011). http://www.tyra.com 
Walker, Susannah. (2007) Style \& Status: Selling Beauty to African American

Women, 1920-1975, The University Press of Kentucky, Lexington.

Watts, Eric and Orbe, Mark. (2002) 'The Spectacular Consumption of 'True' African American Culture: 'Whassup' with the Budweiser Guys?' Critical Studies in Media Communication, vol. 19, no. 1, pp.1-20.

Weber, Brenda. (2009) Makeover TV: Selfhood, Citizenship, and Celebrity, Duke University Press, Durham. 